\title{
LIPIDS AND PLATELET FUNCTION IN RUNNERS
}

\author{
J. R. HAIGH†*, C. A. FRUIN†**, R. PINN $¥$ and E. J. A. LEAT \\ tSchool of Biological Sciences, University of East Anglia, Norwich NR4 TTJ. ¥Norfolk and Norwich Hospital, Norwich \\ * *Present address: Department of Biochemistry, University of Birmingham, Birmingham B15 2 TT
}

\begin{abstract}
The effect of distance running on the fatty acid composition of platelet and erythrocyte membranes has been investigated, together with platelet aggregation and levels of high density lipoprotein-cholesterol (HDLC), low density lipoprotein cholesterol (LDLC), total cholesterol and triglycerides in runners $(n=11)$ and healthy age-matched non-running controls $(n=12)$. Platelet aggregation and fatty acid composition of membrane lipids in both platelets and erhythrocytes are similar in both groups with the following exceptions: in platelets docosahexaenoic acid (C22:6w3) is significantly higher in runners; in erythrocytes the fatty acids $\mathrm{C} 20: 3 \omega 6 / \mathrm{C} 22: 1 \omega 9$ and $\mathrm{C22}: 5 \omega 3$ are significantly higher in runners. There were no significant differences between the levels of HDLC, LDLC and total cholesterol in runners and controls although triglycerides were significantly lower in runners. Possible beneficial effects of running are probably mediated through effects on serum lipid and lipoprotein concentrations, and probably not due to any antithrombotic effect of platelets.
\end{abstract}

Key words: Cardiovascular disease, Exercise, Fatty acids, Lipoproteins, Platelet aggregation

\section{INTRODUCTION}

Coronary heart disease (CHD) is still the leading contributor to mortality in middle age in the developed world (Keys, 1980). Athletics, running, jogging and sports, have become the symbol of protection against heart disease. The role played by lipids and lipoproteins is the subject of controversy. Lipoprotein receptors are believed to control the levels of lipoproteins (Mahley and Innerarity, 1983; Goldstein et al, 1983; Brown and Goldstein, 1984). A functional fault or absence of one particular type of receptor, the low density lipoprotein (LDL) receptor results in the elevated levels of LDL associated with atheroma. Indeed, it has been suggested that LDL in Western man may be unphysiologically high (Brown and Goldstein, 1984). It has been suggested that high density lipoprotein (HDL) involved in transport of cholesterol from tissues of the body is protective (Gordon et al, 1977) although this interpretation of the findings has recently been disputed (Pocock et al, 1986). Platelets, which have also been implicated in the genesis of atheroma (Ross, 1986), play a vital role in the homeostasis of the cardiovascular system. Platelet aggregation, an early event in the chain of reactions leading to formation of thrombosis is partly controlled by two classes of substance: the prostacyclins, and the thromboxanes (Moncada and Vane, 1978; Dyerberg and Bang, 1980; Dyerberg, 1981). Prostacyclins are formed by enzymes in the endothelial linings of healthy blood vessels and are the most potent inhibitors of platelet aggregation known. Thromboxanes are produced by platelets and promote platelet aggregation. Both prostacyclins and thromboxanes are produced from platelet membrane fatty acid substrates (see Fig. 1).

In a number of studies, associations have been described between coronary heart disease and diet (Kannel et al, 1970; Lewis, 1980). Low risk of CHD, low LDL, high HDL and lowered platelet haemostatic functions in Eskimos (Dyerberg, 1981) has been attributed to a marine diet high in polyunsaturated fats. In the "seven countries" study of the

*Present address and address for correspondence:

Department of Biochemistry

University of Edinburgh Medical School

Hugh Robson Building

George Square

Edinburgh EH8 9XD

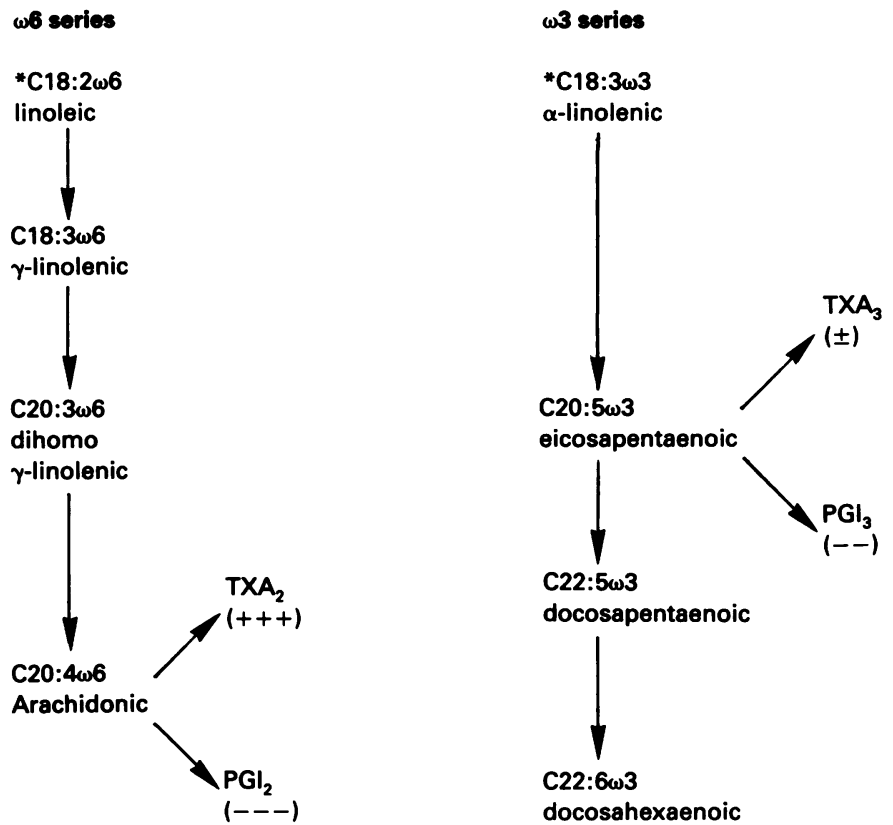

Fig. 1: Chain elongation and desaturation of polyunsaturated fatty acids and their relationship to prostaglandins affecting platelet function. PGI, prostacyclin; TX, thromboxane; +, promotes platelet aggregation and blood vessel vasoconstriction; - , inhibits platelet aggregation and promotes blood vessel vasodilation.

*In the nomenclature of fatty acids, the number after the $C$ refers to the number of carbon atoms, that after the colon to the number of double bonds and $\omega 3$ or $\omega 6$ indicates that the first double bond counting from the methy end is in the 3-position or 6-position, respectively.

relationship of diet and CHD, a positive correlation was found between CHD, saturated fat and total dietary fat (Keys, 1980). More recently Miettinen et al (1982) and Wood et al (1984) have reported an association between, respectively, low serum and adipose tissue linoleic acid (C18:2 $\omega 6)$ and CHD.

Several groups have investigated the effects of exercise on serum lipoproteins. Differences in physical activity protocols, diet and other factors make generalisations difficult; apparent results are variable and inconsistent. This subject has been reviewed thoroughly by Goldberg (1985). However, no reports have appeared in the literature on the effects of long-term exercise on platelet function or platelet and erythrocyte membrane fatty acid composition. 
Against this background, the present study has measured and compared fasting serum lipoprotein levels, in vitro platelet aggregation and platelet and erythrocyte fatty acid profiles in a group of long distance runners with those of a group of age-matched non-running controls.

\section{MATERIALS AND METHODS}

\section{Subjects}

Runners. Nine male and two female runners, members of the University of East Anglia Athletics Club aged 18-29 years (mean \pm SEM:24.0 \pm 1.2 ) were examined. They reported averaging 30-50 miles running per week for the previous six months and were active at the time of the test.

Controls. Eleven men and one woman aged $20-30$ years (mean \pm SEM:22.7 \pm 0.91 ) were used. All were students of the University of East Anglia and reported to undertake no regular strenuous physical exercise.

The results of a $24 \mathrm{~h}$ recall revealed that all subjects followed very similar dietary and alcohol consumption habits, and all were non-smokers.

\section{Blood Samples}

After a $12-14 \mathrm{~h}$ overnight fast, blood $\left(30 \mathrm{~cm}^{3}\right)$ was collected into a polystyrene syringe with attached $21 \mathrm{G}$ needle, without anticoagulant, by venepuncture of a large antecubital vein in the right or left arm.

For platelet aggregation studies blood was mixed with sodium citrate $(3.8 \% \mathrm{w} / \mathrm{v})$, one part to nine parts blood. All analyses took place within two hours of sampling. Plateletrich plasma (PRP) was obtained after centrifugation at $200 \mathrm{~g}$ for $5 \mathrm{~min}$ and platelet-poor plasma (PPP) was obtained after centrifugation at $1500 \mathrm{~g}$ for $15 \mathrm{~min}$. PRP was adjusted using autologous PPP so that it contained $2 \times 10^{8}$ platelets per $\mathrm{cm}^{3}$ of plasma. Platelet aggregation was measured in a dual beam platelet aggregometer (Payton Aggregation Module, Centronic Sales Ltd., Ontario, Canada) which records the change in transmission of light through PRP in vitro. Light transmittance was adjusted to $0 \%$ and $100 \%$ using PRP and PPP respectively.

For each analysis $0.5 \mathrm{~cm}^{3}$ PRP was placed in a small siliconised glass tube at $37^{\circ} \mathrm{C}$ and stirred magnetically at $800 \mathrm{rpm}$. Adenosine Diphosphate (ADP), to final concentration $5.0 \mu \mathrm{mol} . \mathrm{I}^{-1}$ and Arachidonic acid (AA), to final concentration $1.5 \mathrm{mmol} .1^{-1}$ were used to induce a secondary phase platelet aggregation response. For the quantification of data, the time taken from the addition of the aggregating substance until the tangent of the steepest part of the aggregation curve crossed the base line was measured and from this the half-maximal aggregation time $t_{1 / 2}(s)$ calculated. The maximum rate of change in light transmission ( $V_{\max }$ arbitrary units) was calculated from the slope of the steepest part of the aggregation curve.

\section{Preparation of platelets and erythrocytes for} fatty acid analysis

Blood containing $2.47 \mathrm{mM}$ dipotassium EDTA was centrifuged at $150 \mathrm{~g}$ for $20 \mathrm{~min}$ to obtain PRP; the erythrocyte-containing pellet was used for preparation of 'ghosts'. PRP was centrifuged at $1500 \mathrm{~g}$ for $20 \mathrm{~min}$ to obtain PPP. The latter was removed and discarded and the platelet sediment washed with $0.98 \%(w / v) ~ N a C l$ containing $0.5 \mathrm{mM}$ EDTA before lipid extraction.

Lipids were extracted from platelet membranes using chloroform/methanol (1:1). After evaporation of solvents under a stream of nitrogen, fatty acid methyl esters were prepared by acid trans methanolysis and hexane extraction as previously described (Lea and Jones, 1980).

Erythrocyte ghosts were prepared by haemolysis of erythrocytes by the method of Dodge et al (1963) and lipids extracted using chloroform/methanol by a modification to the method described by Folch et al (1957). Fatty acid methyl esters were prepared by acid trans methanolysis as described previously (Lea and Jones, 1980).

Fatty acid methyl esters and sterol products were separated using a Pye 104 gas chromatograph fitted with $2.7 \mathrm{~m}, 2 \mathrm{~mm}$ i.d. glass column (J. J.'s Chromatography Ltd. Kings Lynn, UK) packed with Silar 10C on 100-120 mesh Gashcrom Q (Applied Science Laboratories Inc., USA). Nitrogen was the carrier gas with a flow rate of approximately $10 \mathrm{~cm}^{3} \cdot \mathrm{min}^{-1}$. Fatty acid methyl esters were separated with the temperature programme: initial phase $\left(200^{\circ} \mathrm{C}\right.$ for $\left.10 \mathrm{~min}\right)$ then $200-237^{\circ} \mathrm{C}, 1^{\circ} \mathrm{C} \mathrm{min}^{-1}$. Each sample was run at least two or three times to check the reproducibility of the analysis. The output data was collected using a programmable computing integrator (Columbia Scientific Instruments). The components separated were identified using authentic standards (Supelco) run under identical conditions; methyl esters of the following pairs of fatty acids were considered as complex peaks: C18:3 $\omega 3 / \mathrm{C} 20: 1 \omega 9 ; \mathrm{C} 20: 3 \omega 6 / \mathrm{C} 22: 1 \omega 9$ and C20:5 $\omega 3 / \mathrm{C} 24: 1 \omega 9$. In some cases, $\mathrm{C} 16: 0$ and $\mathrm{C} 16: 1 \omega 9$ could not be resolved and so for uniformity throughout the study these fatty acids were considered together. No attempt was made to determine the relative amounts of the constituents of these peaks in runners and controls.

\section{LIPOPROTEIN ANALYSIS}

Serum cholesterol, triglycerides and HDLc were determined by a density-gradient ultracentrifugation method (Demacker et al, 1984). VLDLc was not measured. HDLc is determined after precipitation of VLDLc and LDLc by polyethylene glycol 6000 (Demacker et al, 1980). The Friedewald formula (Friedewald et al, 1972) is then used to calculate the LDLc:-

$$
\begin{gathered}
\mathrm{LDLC}=\text { Total cholesterol }(\mathrm{TC})-\mathrm{HDLC}-0.45 \times \\
\text { serum triglyceride }
\end{gathered}
$$

\section{STATISTICAL TESTS}

Each fatty acid peak was expressed as a mass percentage of the total fatty acids present. These percentages are relative and hence interdependent. Each of the distributions compared was tested and found to be normal using the Kolmogorov-Smirnov one-sample test.

The statistical significance of the differences between the means for the platelet and erythrocyte fatty acids and the platelet aggregation responses in the two groups was determined using the two-tailed Students t-test. Means, standard errors of the means and Pearson product-moment correlation coefficients were calculated by ordinary methods.

\section{RESULTS}

In the present study two groups of subjects, eleven long distance runners, averaging 30-50 miles running per week, and twelve healthy non-running controls were investigated with regard to the fatty acid composition of platelet and erythrocyte membranes and platelet aggregation. 


\section{Platelet and erythrocyte membrane fatty acids}

The distribution of fatty acids in platelets is shown in Table I. The relative levels of $C 16: 0 / C 16: 1 \omega 9, C 18: 0$ and $C 18: 1 \omega 9$ are higher in controls than runners although these differences are not significant. Generally, the levels of polyunsaturated fatty acids in platelets are higher in runners than controls, with the exception of $\mathrm{C} 18: 2 \omega 6$ and $\mathrm{C} 20: 4 \omega 6$. The only significant difference between the two groups is that runners have higher levels of $\mathrm{C22:6 \omega 3}$ in their platelets compared with controls. The fatty acid composition of erythrocyte membranes is also very similar in both groups, with the exception of significantly raised values in the runners for the component $\mathrm{C} 20: 3 \omega 6 / \mathrm{C} 22: 1 \omega 9(2.5 \% \pm 0.4$ for runners, $1.2 \% \pm 0.3$ for controls, mean \pm SEM; $p<0.05$ ) and for $\mathrm{C} 22: 5 \omega 3 \mathrm{~B}(3.7 \% \pm 0.9$ for runners, $1.3 \% \pm 0.3$ for controls, mean \pm SEM; $p<0.05)$.

TABLE I

Principal fatty acids in platelet membranes of runners and controls

\begin{tabular}{|c|c|c|c|}
\hline & $\begin{array}{l}\text { Controls } \\
(n=12)\end{array}$ & $\begin{array}{l}\text { Runners } \\
(n=11)\end{array}$ & $\begin{array}{l}\text { Students } \\
\text { t value }\end{array}$ \\
\hline $\mathrm{C} 16: 0 / \mathrm{C} 16: 1 \omega 9$ & $19.8 \pm 0.5$ & $19.3 \pm 0.9$ & 0.5 \\
\hline C18:0 & $17.2 \pm 0.3$ & $16.7 \pm 0.4$ & 0.8 \\
\hline 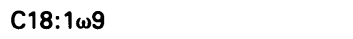 & $21.6 \pm 0.7$ & $19.7 \pm 0.9$ & 1.5 \\
\hline$C 18: 2 \omega 6$ & $6.4 \pm 0.4$ & $6.3 \pm 0.2$ & 0.0 \\
\hline 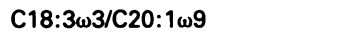 & $1.1 \pm 0.1$ & $1.4 \pm 0.2$ & 0.9 \\
\hline$C 20: 2 \omega 6$ & $2.5 \pm 0.1$ & $2.5 \pm 0.2$ & 0.1 \\
\hline 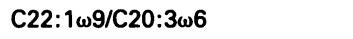 & $2.1 \pm 0.1$ & $2.6 \pm 0.2$ & 1.9 \\
\hline$C 20: 4 \omega 6$ & $22.3 \pm 0.4$ & $21.8 \pm 1.2$ & 0.3 \\
\hline $\mathrm{C} 20: 5 \omega 3 / \mathrm{C} 24: 1 \omega 9$ & $1.9 \pm 0.1$ & $2.4 \pm 0.3$ & 1.4 \\
\hline $\mathrm{C} 22: 5 \omega 3$ & $2.1 \pm 0.1$ & $2.4 \pm 0.3$ & 0.6 \\
\hline $\mathrm{C} 22: 6 \omega 3$ & $2.6 \pm 0.1$ & $3.7 \pm 0.4$ & $2.3^{*}$ \\
\hline $\begin{array}{l}\Sigma \text { saturated fatty acids } \\
(C 16: 0 / C 16: 1 \omega 9+C 18: 0)\end{array}$ & $37.0 \pm 0.4$ & $36.0 \pm 0.65$ & \\
\hline $\begin{array}{l}\Sigma \text { polyunsaturated fatty acids } \\
(C 18: 2 \omega 6 \rightarrow C 22: 6 \omega 3)\end{array}$ & $41.0 \pm 0.07$ & $43.1 \pm 0.14$ & \\
\hline
\end{tabular}

Results are expressed as relative percentages by weight of total fatty acids present (mean \pm SEM)

Significance: ${ }^{*} p<0.05$

\section{Platelet aggregation}

The results of platelet aggregation responses are shown in Table II. The half maximal aggregation times $\left(t_{1 / 2} \sec \right)$ induced by the separate addition of the aggregating agents $A D P$ and $A A$ to platelet-rich plasma in vitro were not significantly different between the two groups, although, as expected, the half maximal aggregation times of ADPstimulated platelets in both runners and controls is less than $50 \%$ of that AA-stimulated platelets, due to the direct aggregatory effect of ADP on the platelet membrane surface (Zuckerman, 1980). The maximum rate of platelet aggregation $\left(V_{\max }\right)$, whether induced by ADP or AA was not significantly different between runners and controls.

\section{Serum lipoprotein measurements}

Serum LDLc, HDLc, total cholesterol and triglycerides were measured in both groups. These are shown in Table III. The runners showed slightly higher LDLc and HDLC and slightly lower total cholesterol than controls. Triglycerides were significantly lower in runners compared with controls.
TABLE II

Platelet aggregation responses in runners and controls after addition of aggregating agents Adenosine Diphosphate (ADP) and Arachidonic Acid (AA) to platelet-rich plasma in vitro

\begin{tabular}{lcccc}
\hline & $\begin{array}{c}\text { Half-maximal aggregation } \\
\text { time }\left(\mathrm{t}_{1 / 2} \text { sec) }\right. \\
\text { ADP }\end{array}$ & $\begin{array}{c}\text { Max rate of change in } \\
\text { light transmittance }\end{array}$ \\
\hline $\begin{array}{l}\text { Runners } \\
\text { (n=11) }\end{array}$ & $25.3 \pm 0.8$ & $65.8 \pm 8.8$ & $3.7 \pm 0.2$ & $3.4 \pm 0.6$ \\
$\begin{array}{l}\text { Controls } \\
\text { (n=12) }\end{array}$ & $23.8 \pm 0.6$ & $54.4 \pm 4.4$ & $4.1 \pm 0.2$ & $3.9 \pm 0.3$ \\
$\begin{array}{l}\text { Student's } \\
\text { t-test }\end{array}$ & 1.3 & 1.1 & 1.2 & 0.7 \\
\hline
\end{tabular}

Results are expressed as mean \pm SEM

$1_{\mathrm{au}}=$ arbitrary units

TABLE III

Serum lipoprotein levels

\begin{tabular}{llc}
\hline Lipoprotein & $\begin{array}{c}\text { Controls } \\
(\mathrm{n}=12) \\
(\mathrm{mmol} / / \text {; mean } \pm \mathrm{SEM})\end{array}$ & $\begin{array}{c}\text { Runners } \\
(\mathrm{n}=11)\end{array}$ \\
\hline HDLC & $1.15 \pm 0.09$ & $1.2 \pm 0.12$ \\
LDLC & $2.48 \pm 0.32$ & $2.87 \pm 0.19$ \\
Total cholesterol & $4.65 \pm 0.26$ & $4.51 \pm 0.26$ \\
Triglyceride & $1.36 \pm 0.39$ & $0.86 \pm 0.9^{*}$ \\
\hline
\end{tabular}

Significance: ${ }^{*} p<0.05$

\section{DISCUSSION}

\section{Correlations between fatty acids}

In correlations calculated between platelet fatty acid pairs for runners and for controls only one pair reached signifi-

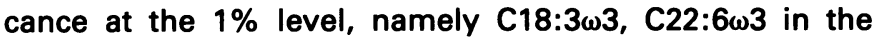
control group $(r=0.78, n=12)$. For the combined data i.e. runners and controls taken together, three pairs reached significance at the $1 \%$ level and were all inversely

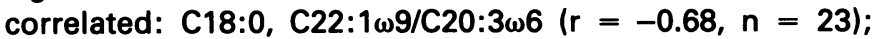
$C 18: 1 \omega 9, C 18: 2 \omega 6(r=-0.59, n=23)$; and C18: $1 \omega 9, C 22: 5 \omega 3$ $(r=-0.57, n=23)$. The previously reported significant inverse correlation between relative levels of $C 18: 2 \omega 6$ and

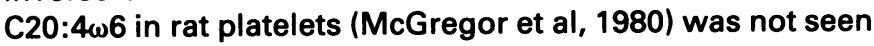
here.

In erythrocytes, a longer-term and thus more reliable indicator of fatty acid metabolism than platelets on account of longer lifetime (Lea et al, 1980), significant positive correlations were found in the combined data between C18:2 $\omega 6$ and its long chain derivative $C 20: 4 \omega 6(r=0.63, n=$

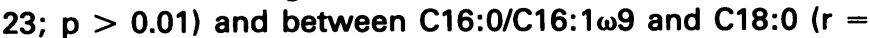
$0.90, n=23 ; p>0.01)$. These confirm expected physiological relationships between fatty acids.

\section{Serum lipoprotein measurements}

In addition to studies of dietary fat intake on erythrocyte and platelet lipid composition and on platelet function, a large amount of experimental work has been carried out in recent years on the influence of dietary manipulation on lipoprotein metabolism, and in particular on serum lipoprotein concentrations. The influence of increased levels of exercise on serum lipoproteins has been an active 
research area since about 1975, when considerable evidence began to emerge suggesting that altered concentrations of serum lipoproteins may offer a protective effect against the development of coronary heart disease (Miller and Miller, 1975; Castelli et al, 1975).

It has been reported that individuals engaging in relatively higher amounts of physical activity, such as runners and tennis players, tend to have lower levels of plasma LDL, VLDL (and consequently triglycerides), and higher levels of HDL than their sedentary counterparts (Wood et al, 1977; Goldberg and Elliot, 1985; Wood et al, 1980). These serum lipoprotein distributions have been associated with a reduced risk of cardiovascular disease, suggestions which have been recently disputed (Pocock et al, 1986).

In a prospective study (Gordon et al, 1977), incidence of coronary heart disease was expressed as a function of seven HDL levels: below 0.65 , above 1.95 and five $0.26 \mathrm{mmol} . \mathrm{I}^{-1}$ bands between 0.65 and 1.95 , the median band being the $0.65-0.91 \mathrm{mmol}^{-1} \mathrm{I}^{-1}$ one.

In the present study the SE's are smaller than the band widths of Gordon et al (1977), i.e. an examination of changes in HDL levels and CHD risk factors is feasible in this study, in spite of the small numbers used, and it has thus to be concluded that there is no significant difference in risk factors between the two groups.

No significant correlations were found between the serum lipoprotein levels, platelet fatty acids or in vitro platelet aggregation responses. This is consistent with the results of Nordoy et al (1979) who found no significant differences in in vitro platelet function in two groups of male subjects: one with low (mean $1.03 \mathrm{mmol} . \mathrm{I}^{-1}$ ) and the other with high (mean $1.80 \mathrm{mmol}^{-1}$ ) concentrations of HDL-cholesterol as well as the results of Boberg et al (1985) and Salo et al (1985) who found no significant correlations between serum lipoproteins, platelet phospholipid fatty acids and platelet aggregation responses in normal male subjects.

In both runners and controls only very weak correlations exist between serum lipoprotein levels and the fatty acids of erythrocyte membranes, although in the combined data significant correlations were observed between HDLc and C18:1 $\omega 9$ and $C 22: 5 \omega 3$ and between total cholesterol and

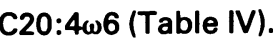

TABLE IV

Relationships between serum lipoproteins and erythrocyte fatty acids (combined data)

\begin{tabular}{|c|c|c|}
\hline Lipoprotein & Fatty acid & Correlation coefficient \\
\hline \multirow[t]{2}{*}{ HDLc } & C18:1w9 & -0.64 \\
\hline & $\mathrm{C} 22: 5 w 3$ & 0.85 \\
\hline Total cholesterol & $\mathrm{C} 20: 4 \omega 6$ & -0.66 \\
\hline
\end{tabular}

Correlation coefficients shown are significant at the $5 \%$ level

Triglyceride levels were significantly lower in athletes and an inverse correlation $(r=-0.72, p<0.05)$ was found between HDLc and triglyceride in the combined data, a value similar to that observed previously for human serum of healthy male subjects (Nordoy, 1979). Interestingly, a strong positive relationship $(r=0.69, p<0.05)$ was found between LDLc and triglyceride in the combined data.
Several studies have indicated that vigorous exercise training may result in elevated HDLc (Wood et al, 1977; Wood et al, 1980), although it appears that differences in HDLc concentration between populations probably reflect differences in the capacity to handle varying amounts of dietary fat (Knuiman and West, 1983). Hartung et al (1980) investigated the relation between diet and plasma lipid and lipoprotein levels in middle-aged marathon runners, joggers and inactive men; their results suggest that the significantly raised levels of HDLc and lowered levels of triglycerides in runners and joggers compared with inactive subjects were primarily due to distance run, and not dietary factors.

It is not clear why the changes in serum lipoprotein concentrations observed in the present study are not as marked or significant as those reported in other studies that describe comparable increases in the level of physical activity undertaken.

Higher levels of physical activity are also associated with a greater degree of cardiovascular fitness, lower adiposity (expressed as percentage body fat) and increased intake of calories, notably in the form of carbohydrate; the latter two factors themselves have independent roles in the regulation of lipoprotein levels. These changes have been observed in a study of middle-aged men engaged in an uncontrolled progressive running programme over 2 years; in addition HDL is increased and LDL decreased (Wood et al, 1985); thus it appears that elevated physical activity alters the relationship among dietary intake, lipoproteins and adiposity that prevail in the sedentary state. This study has shown that consistently increased levels of physical activity, in the form of running 30-50 miles per week result in small changes in the fatty acid composition of platelet and erythrocyte membranes and serum lipids, with the exception of triglycerides, which are significantly reduced. Long distance running does not appear to influence haemostatic platelet function.

If altered serum lipid and lipoprotein concentrations are related to the development of cardiovascular disease, the present study may indicate that this is not due to a direct effect of lipids and lipoproteins on platelets.

\section{ACKNOWLEDGEMENTS}

We wish to thank Mrs. Judith Lea for phlebotomy, Dr. T. Tickner for the serum lipoprotein measurements and Dr. R. A. Riemersma of the Cardiovascular Research Unit, University of Edinburgh, for many helpful discussions.

\section{References}

Boberg, M., Croon, L. B., Gustafesson, I. B. and Vessby, B., 1985 "Platelet fatty acid composition in relation to fatty acid composition in plasma and to serum lipoprotein lipids in healthy subjects with special reference to the linoleic acid pathway". Clinical Science 68: 581-587.

Brown, M. S. and Goldstein, J. L., 1984 "How LDL receptors influence cholesterol and atherosclerosis". Scientific American 251: 52-60.

Castelli, W. P., Doyle, J. T., Gordon, T., Hames, C., Hulley, S. B., Kagan, A McGee, D., Vici, W. J. and Zukel, W. J., 1975 "HDL-cholesterol levels in coronary heart disease (CHD): A co-operative lipoprotein phenotyping study". Circulation 52 (Suppl. 2): 97.

Demacker, P. N., Hijmans, A. G. and Vos-Janssen, H. E., 1980 "A study of the use of polyethylene glycol in estimating cholesterol in high density lipoprotein". Clinical Chemistry 26: 1775-1779.

Demacker, P. N., Hijmans, A. G., Brenninkjeijer, B. J. et al, 1984 "Five methods for determining low density lipoprotein cholesterol compared". Clinical Chemistry 30: 1797-1800.

Dodge, J. T., Mitchell, C. and Hanahan, D. J., 1963 "The preparation and chemical characteristics of haemoglobin free ghosts of human erythrocytes". Archives of Biochemistry and Biophysics 100: 119-130. 
Dyerberg, J. and Bang, H. O., 1980 "All cis-5,8,11,14,17 eicosapentaenoic acid and triene prostaglandins: potential antithrombotic agents". Scandinavian Journal of Clinical and Laboratory Investigation 40: 589-593.

Dyerberg, J., 1981 "Platelet-vessel wall interaction: influence of diet". Philosophical Transactions of the Royal Society (London) 294: 373-381.

Folch, J., Lees, M. and Sloane-Stanley, G. H., 1957 "A simple method for the isolation and purification of total lipids from animal tissue". Journal of Biological Chemistry 226: 497-509.

Friedewald, W. T., Levy, R. and Fredrickson, D. S., 1972 "Estimation of the concentration of low density lipoprotein cholesterol in plasma without the use of the preparative centrifuge". Clinical Chemistry 18: 499-502.

Goldberg, L. and Elliott, D. L., 1985 "The effect of physical activity on lipid and lipoprotein levels". Medical Clinics of North America 69: 41-55.

Goldstein, J. L., Kita, T. and Brown, M. S., 1983 "Defective lipoprotein receptors and atherosclerosis: lessons from an animal counterpart of familial hypercholesterolemia". New England Journal of Medicine 309: 288-296.

Gordon, T., Castelli, W. P., Hjortland, M. C. et al, 1977 "High-density lipoprotein as a protective factor against coronary heart disease: The Framingham Study". American Journal of Medicine 62: 707-714.

Hartung, G. H., Foreyt, J. P., Mitchell, R. E., Vlasek, I. and Gotto, A. M., 1980 "Relation of diet to HDL-cholesterol in middle aged marathon runners, joggers and inactive men". New England Journal of Medicine 302 (7): 357-361.

Kannel, W. D. and Gordon, T. eds., 1970 "The Framingham Study: an epidemiological investigation of cardiovascular disease Section 24. Diet and the regulation of serum cholesterol". Washington D.C.: Government Printing Office.

Keys, A., 1980 "Seven countries: a multivariate analysis of death and coronary heart disease". Cambridge: Harvard University Press.

Knuiman, J. T. and West, C. E., 1983 "Differences in HDL cholesterol between populations: no paradox? Lancet i: 296.

Lea, E. J. A. and Jones, S. P., 1980 "Simultaneous measurement of sterol and fatty acid composition in small samples". Journal of Chromatography 221: 367-370.

Lea, E. J. A., Jones, S. P. and Hamilton, D. V., 1982 "The fatty acids of erythrocytes of myocardial infarction patients". Atherosclerosis 41: 363-369.
Lewis, B., 1980 "Dietary prevention of ischaemic heart disease - a policy for the '80's". British Medical Journal (ii): 177-180.

Mahley, R. W. and Innerarity, T. L., 1983 "Lipoprotein receptors and cholesterol homeostasis". Biochmica et Biophysica Acta 737: 197-222.

McGregor, L., Morazain, R. and Renaud, S., 1980 "Effect of dietary linoleic acid on platelet function in the rat". Thrombosis Research 20: 499-507.

Miettinen, T. A., Naukkarinen, V., Huttunen, J. K., Mattila, S.and Kumlin, T. 1982 "Fatty acid composition of serum lipids predicts myocardial infarction". British Medical Journal 285: 993-996.

Miller, G. J. and Miller, N. E., 1975 "Plasma high-density lipoprotein concentrations and the development of ischaemic heart disease". Lancet $i$ : 16-19.

Moncada, S. and Vane, J. R., 1978 "Unstable metabolites of arachidonic acid and their role in haemostasis and thrombosis". British Medical Bulletin 34: 129-135.

Nordoy, A., Refsum, N., Thelle, D. and Jaeger, S., 1979 "Platelet function and serum High Density Lipoproteins". Thrombosis and Haemostasis 42 1181-1186.

Pocock, S. J., Shaper, A. G., Philips, A. M. et al., 1986 "High density lipoprotein cholesterol is not a major risk factor for ischaemic hear disease in British men". British Medical Journal 292: 515-519.

Ross, R., 1986 "The pathogenesis of atherosclerosis - an update". New England Journal of Medicine 314: 488-500.

Salo, M. K., Vartianen, E., Puska, P. and Nikkari, T., 1985 "Platelet aggregation in Finnish men and its relation to fatty acids in platelets, plasma and adipose tissue". Thrombosis and Haemostasis 54 (3): 563-569.

Wood, D. A., Butler, S., Riemersma, R. A. et al, 1984 "Adipose tissue and platelet fatty acids and coronary heart disease in Scottish men". Lancet ii 117-121.

Wood, P. D., Haskell, W. L., Stern, M. P., Lewis, S. and Perry, C., 1977 “Plasma lipoprotein distributions in male and female runners". Annals of the New York Academy of Sciences 301: 748-763.

Wood, P. D., Vodak, P. A., Haskell, W. L. and Williams, P. T., 1980 “HDLcholesterol and other plasma lipid and lipoprotein concentrations in middle-aged male and female tennis players". Metabolism 29: 745-752.

Wood, P. D., Terry, R. B. and Haskell, W. L., 1985 "Metabolism of substrates: diet, lipoprotein metabolism, and exercise". Federation Proceedings 44 358-363.

Zuckerman, M. B., 1980 "The functioning of blood platelets". Scientific American 242 (6): 70-84.

Title: $\quad$ SPORTS INJURIES AND THEIR MANAGEMENT

Author: $\quad$ A.P. Millar 1987

Publisher: Williams \& Wilkins

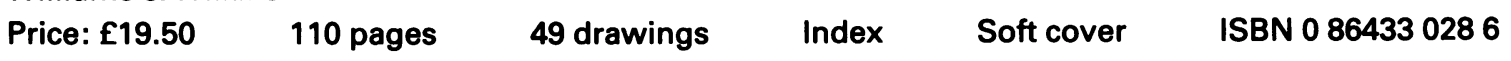

Mr. Millar has written a short book (110 pages from preface to index inclusive) that reviews those sports injuries that have been seen at the Institute of Sports Medicine, Sydney, over the last twenty years. Apart from a couple of pages on heat injury (presumably reflecting the incidence of heat collapse in Australian fun runs) the text exclusively deals with soft tissue injuries. It is concise; within each topic a summary of history, diagnostic findings and principles of therapy are contained. No references are quoted. It is written specifically for the doctor of first contact and in this respect it succeeds handsomely - it is tempting, though fallacious, to write for too many groups simultaneously (athletes, coaches, trainers, physiotherapist, and medical practitioners).

Although budding sports injury specialists will require greater in-depth knowledge on a number of topics this soft-backed book provides enough information for the non-specialist to attempt an initial assessment of the sports injured and thereby to institute an appropriate management schedule.

Michael A. Hutson 